\title{
Article \\ Physical Comorbidities and Depression in Recent and Long-Term Adult Cancer Survivors: NHANES 2007-2018
}

\author{
Dafina Petrova 1,2,3,*iD, Andrés Catena ${ }^{4}$, Miguel Rodríguez-Barranco 1,2,3 ${ }^{(D)}$, Daniel Redondo-Sánchez ${ }^{1,2,3} \mathbb{D}_{\text {, }}$ \\ Eloísa Bayo-Lozano $^{5}$, Rocio Garcia-Retamero ${ }^{4,6}$, José-Juan Jiménez-Moleón 1,3,7 (D) and María-José Sánchez 1,2,3,7 (D)
}

1 CIBER of Epidemiology and Public Health (CIBERESP), 28029 Madrid, Spain; miguel.rodriguez.barranco.easp@juntadeandalucia.es (M.R.-B.); daniel.redondo.easp@juntadeandalucia.es (D.R.-S.); jjmoleon@ugr.es (J.-J.J.-M.); mariajose.sanchez.easp@juntadeandalucia.es (M.-J.S.)

2 Escuela Andaluza de Salud Pública, 18080 Granada, Spain

3 Instituto de Investigación Biosanitaria ibs.GRANADA, 18012 Granada, Spain

4 Mind, Brain and Behavior Research Center, University of Granada, 18071 Granada, Spain; acatena@ugr.es (A.C.); rretamer@ugr.es (R.G.-R.)

5 Department of Radiation Oncology, University Hospital Virgen Macarena, 49009 Seville, Spain; eloisa.bayo.sspa@juntadeandalucia.es

6 Harding Center for Risk Literacy, 14195 Berlin, Germany

7 Department of Preventive Medicine and Public Health, University of Granada, 18071 Granada, Spain

check for updates

Citation: Petrova, D.; Catena, A.; Rodríguez-Barranco, M.;

Redondo-Sánchez, D.; Bayo-Lozano, E.; Garcia-Retamero, R.; Jiménez-Moleón, J.-J.; Sánchez, M.-J. Physical Comorbidities and Depression in Recent and Long-Term Adult Cancer Survivors: NHANES 2007-2018. Cancers 2021, 13, 3368. https://doi.org/10.3390/ cancers 13133368

Academic Editors: Philip R. Debruyne and Patricia Schofield

Received: 7 June 2021

Accepted: 3 July 2021

Published: 5 July 2021

Publisher's Note: MDPI stays neutral with regard to jurisdictional claims in published maps and institutional affiliations.

Copyright: (C) 2021 by the authors. Licensee MDPI, Basel, Switzerland. This article is an open access article distributed under the terms and conditions of the Creative Commons Attribution (CC BY) license (https:// creativecommons.org/licenses/by/ $4.0 /)$.
Simple Summary: Most cancer patients suffer one or more physical comorbidities (other somatic diseases present at the moment of cancer diagnosis). Previous research has shown that these comorbidities can interfere with cancer treatment and shorten the patient's survival time. We propose that comorbidities could also interfere with the mental health of cancer patients and increase the risk of suffering depression in the years following the cancer diagnosis. We tested this possibility in a study of 2073 adult cancer survivors. We found that the number of physical comorbidities present at the moment of cancer diagnosis was related to higher risk of reporting depression in cancer survivors who were diagnosed up to 5 years before the study. This relationship was strongest among survivors of breast cancer. Information about comorbidities is usually readily available and could be useful in streamlining depression screening or targeting prevention efforts in cancer patients and survivors.

\begin{abstract}
Many adult cancer patients present one or more physical comorbidities. Besides interfering with treatment and prognosis, physical comorbidities could also increase the already heightened psychological risk of cancer patients. To test this possibility, we investigated the relationship between physical comorbidities with depression symptoms in a sample of 2073 adult cancer survivors drawn from the nationally representative National Health and Nutrition Examination Survey (NHANES) (2007-2018) in the U.S. Based on information regarding 16 chronic conditions, the number of comorbidities diagnosed before and after the cancer diagnosis was calculated. The number of comorbidities present at the moment of cancer diagnosis was significantly related to depression risk in recent but not in long-term survivors. Recent survivors who suffered multimorbidity had 3.48 (95\% CI 1.26-9.55) times the odds of reporting significant depressive symptoms up to 5 years after the cancer diagnosis. The effect of comorbidities was strongest among survivors of breast cancer. The comorbidities with strongest influence on depression risk were stroke, kidney disease, hypertension, obesity, asthma, and arthritis. Information about comorbidities is usually readily available and could be useful in streamlining depression screening or targeting prevention efforts in cancer patients and survivors. A multidimensional model of the interaction between cancer and other physical comorbidities on mental health is proposed.
\end{abstract}

Keywords: cancer; comorbidity; mental health; depression; cancer survivors 


\section{Introduction}

Many studies show that cancer patients and survivors frequently suffer from psychological problems. Compared to the general population, individuals diagnosed with cancer are more likely to experience psychological distress or suffer common mental disorders such as depression, anxiety, adjustment, or post-traumatic stress disorder [1-4]. Depressive spectrum disorders are among the most common, with an estimated prevalence of around $16 \%(13 \%$ to $20 \%)$ across oncological, hematological, and palliative settings [5].

The prevalence of depression is higher among patients with a previous history of psychiatric conditions and varies as a function of the type of cancer diagnosed, the stage of disease, the treatment employed, and the time elapsed since the cancer diagnosis, among others [6-11]. Risk factors for developing depression include having lung, pancreas, head/neck or brain cancer, advanced or metastatic disease, a personal or family history of mental disorders, and being treated with certain chemotherapy agents [6]. Generally, the prevalence of depression is highest during the first year after diagnosis $[8,10]$. The prevalence of depression in long-term survivors (e.g., $>5$ years after diagnosis) has been found to be lower and similar to that of the general population without cancer history $[8,9]$.

Another factor to consider is physical comorbidity, defined as other somatic health conditions in addition to the primary disease of interest [12]. Due to the advanced age of most cancer patients and the shared predisposing factors between cancer and other highly prevalent chronic diseases, it is common for cancer patients to suffer from one or more physical comorbidities [13]. In fact, cancer patients report more comorbidities compared to controls without cancer history [3,4]. Physical comorbidities are important in cancer care because they can limit the possibility to receive some treatments, increase their toxicity, or delay their initiation [13-15]. Most importantly, patients with more comorbidities have a poorer prognosis compared to those without other pre-existing conditions [14,16].

Physical comorbidities could also deteriorate the mental health of cancer patients and survivors. Depression is generally more common in adults with chronic health problems compared to people who have good physical health [17]. In cancer patients with diverse diagnoses, each additional physical comorbidity is associated with $9 \%$ higher odds of reporting high psychological distress [4].

The diagnosis of cancer is a significant life-changing event, and many cancer treatments have high toxicity or result in disfigurement, worsening the quality of life of patients. These difficult circumstances could bring about a period of high psychological vulnerability, in which co-existent physical comorbidities play a key role. Among cancer patients, both physical comorbidities and depression are significantly associated with greater healthcare utilization $[4,18]$. This suggests that effective prevention, screening, and management of depression in comorbid patients can help reduce healthcare utilization and cost while improving the care and quality of life of patients [18].

In the oncologic setting, depression is meant to be detected via regular screening for distress. Comprehensive clinical guidelines for the screening and management of distress in oncologic setting already exist in several countries [19]. In the U.S., the National Comprehensive Cancer Network (NCCN) Clinical Practice Guidelines in Oncology on distress management recommend that at a minimum, all patients should be screened for distress at the initial visit, at appropriate intervals, and as clinically indicated, especially with changes in disease status such as recurrence or treatment complications [20]. The NCCN Guidelines consider patients with "severe comorbid illness" to be at high risk for distress. However, it is possible that the co-existence of multimorbidity (two or more comorbidities in addition to the disease of interest) could affect distress and consequently depression risk regardless of the severity of comorbidities. For instance, conditions such as migraines, chronic back pain, and urinary incontinence have been significantly related to reporting significant psychological distress in cancer patients [4].

More detailed knowledge about to what extent, when, and for whom physical comorbidities negatively influence mental health could ultimately help streamline screening (e.g., more frequent screening in comorbid patients with specific diagnoses). This would 
be useful in lower resource settings where distress screening and management remains a luxury but also in higher resource setting where, despite comprehensive guidelines, a large number of patients remain unscreened $[19,21]$.

The aim of this study was to investigate the relationship between physical comorbidities and depression in cancer survivors. Based on a previously documented relationship between physical comorbidities and psychological distress in cancer patients [4], we hypothesized that a higher physical comorbidities burden would be related to higher depression risk in cancer survivors. Given the previously documented heterogeneity in depression prevalence among survivors, we investigated how this relationship varied as a function of the time in survivorship (recent vs. long-term) and the type of cancer diagnosed. In addition, besides the total number of physical comorbidities present, we investigated to what extent only those diagnosed before the cancer predicted depression during survivorship, because they could potentially be a useful baseline assessment to guide psychological screening after diagnosis. Finally, we investigated which specific comorbidities most strongly contributed to depression.

\section{Materials and Methods}

\subsection{Study Population}

We obtained data from the National Health and Nutrition Examination Survey (NHANES), a periodic cross-sectional survey of the U.S. population [22]. The survey uses a complex, multistage probability sampling to obtain a nationally representative sample of about 5000 people each year. The NHANES samples represent the noninstitutionalized civilian population residing in the 50 states and the District of Columbia. The sample design consists of multi-year, stratified, clustered four-stage samples, with data release in 2-year cycles. The NHANES sample is drawn in four stages: (a) primary sampling units (PSUs) (counties, groups of tracts within counties, or combinations of adjacent counties), (b) segments within PSUs (census blocks or combinations of blocks), (c) dwelling units (DUs) (households) within segments, and (d) individuals within households. PSUs are sampled from all U.S. counties.

For the current study, we combined data from the 2007 to 2018 waves $(59,842$ respondents), covering 12 years. The survey was approved by the National Center for Health Statistics Institutional Review Board. All study participants provided informed consent.

A flow chart of the study sample selection process is displayed in Figure 1. The inclusion criteria for the current study were having been diagnosed with cancer when 18 years old or older and having full or imputable data on the depression assessment (at least 8 out of 9 questions answered) $(n=2869)$. A cancer diagnosis was defined as a "yes" response to the interview question, "Have you even been told by a doctor or other health professional that you had cancer or a malignancy of any kind?". Respondents were then excluded if they reported more than one cancer $(n=302)$, answered "I don't know" to the question about the type of cancer diagnosed $(n=10)$, or were 80 years old or older $(n=484)$. This last criterion was applied because the age of individuals $\geq 80$ is censored at 80 years for privacy concerns; however, exact age was necessary to conduct the current study. The final sample size was $n=2073$ and this was further divided into recent survivors $(n=853$, diagnosed in the past 5 years) and long-term survivors $(n=1220$, diagnosed more than 5 years ago) following Brandenbarg et al. [9].

For a comparison of depression prevalence, one "control" sample of equal size and matched on survey wave, sex, age, and race was obtained for each sub-population from among survey participants who reported no previous cancer history. When no exact age match was available ( $n=7$ for recent and $n=17$ for long-term survivors), age was set at \pm 1 year until a match was found. 


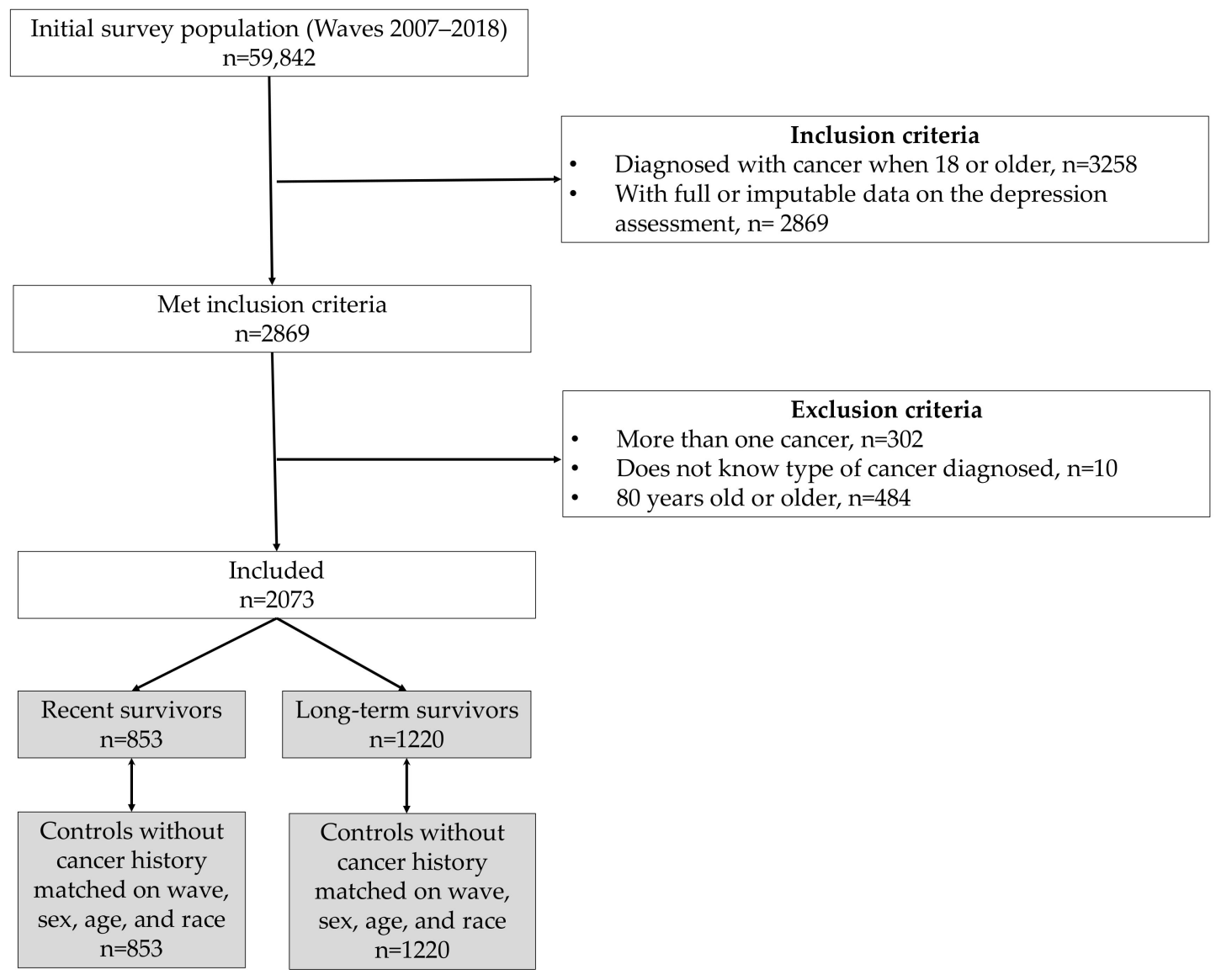

Figure 1. Flow chart describing the study sample selection process.

\subsection{Variables}

\subsubsection{Sociodemographic Characteristics}

Data were obtained on self-reported sex, age (continuous and grouped as 18-39, 40-59, and 60-79), race (Non-Hispanic White, Mexican American, Other Hispanic, Non-Hispanic Black, and Other), education level (up to 11th grade, high school graduate/General Educational Development (GED), some college or associate's (AA) degree, and college graduate or above), civil status (married/living with partner, single, divorced/separated, and widowed), and health insurance status (insured vs. non-insured).

\subsubsection{Physical Function Limitations}

The participants were categorized into three groups: "no limitations", "limited", and "disabled", based on responses to several questions in the Physical Limitations module of the survey, following an established algorithm described in detail elsewhere [23]. The "disabled" group included individuals who reported needing special equipment to walk or having more than some difficulty with any of the following: walking between rooms on the same level, standing up from an armless straight chair, getting in and out of bed, eating (including holding a fork, cutting food or drinking from a glass), dressing (including tying shoes, working zippers, and doing buttons), reaching up over head, or using fingers to grasp or handle small objects. The "limited" group included individuals who only had some difficulty with the above activities or any difficulty walking up ten steps or walking for a quarter mile. The remaining individuals were allocated to the "no limitations" group.

\subsubsection{Cancer Site}

Cancer groups were defined by anatomical site or system affected following the National Cancer Institute [24]: skin non-melanoma (SNM), melanoma, skin unknown 
type, breast (female), gynecological (cervix, ovary, uterus), genitourinary (prostate, bladder, kidney, testis), and digestive/gastrointestinal (colon, rectum, esophagus, gallbladder, liver, pancreas, stomach). The remaining cancer groups with very few respondents were grouped under "Other" (e.g., lung, lymphoma, leukemia, etc., see Table A1 in the Appendix A).

\subsubsection{Time Since Diagnosis}

This was calculated as the difference between the participant's current self-reported age and the age they reported in answer to the question "How old were you when the cancer was first diagnosed?". This was then grouped in 1-year intervals for the sample of recent survivors and intervals of "6-10 years", "11-20 years", and "20+ years" for long-term survivors.

\subsubsection{Physical Comorbidities}

We used data regarding 16 self-reported physical chronic conditions which were consistently and continuously assessed in all relevant waves of the survey: angina pectoris, arthritis, asthma, chronic bronchitis, congestive heart failure, coronary heart disease, diabetes, emphysema, gout, hypertension, liver condition, myocardial infarction, obesity, stroke, thyroid problems, and kidney disease. Participants were classified as suffering each comorbidity if they answered "Yes" to the question "Has a doctor or other health professional ever told you that you have [condition]?". One exception was obesity, defined as a lifetime maximum self-reported body-mass index $\geq 30$, based on questions about participants' current height and self-reported greatest weight. The total number of comorbidities was calculated and divided into groups of " 0 ", " 1 ", " 2 ", and " 3 or more" for descriptive purposes and groups of " 0 " (no comorbidity), " 1 " (comorbidity), and " 2 or more" (multimorbidity) for analysis following [15].

\subsubsection{Physical Comorbidities Pre- and Post-Diagnosis}

For each comorbidity, participants reported the age at which it was first diagnosed from which we determined whether it occurred before the cancer diagnosis or about at the same time or after. We then calculated the number of comorbidities participants had diagnosed before their cancer diagnosis (pre-diagnosis) and the number of comorbidities they had diagnosed at the same time or after the cancer (post-diagnosis).

\subsubsection{Depression}

This was assessed with the Patient Health Questionnaire-9 (PHQ-9) questionnaire, which is a valid self-report instrument based on the DSM-IV criteria for diagnosis of depressive disorder $[25,26]$. It consists of nine items scored from 0 to 3 , resulting in a total score between 0 and 27. The items assess anhedonia, depressed mood, sleep, energy, appetite, guilt and worthlessness, concentration, feeling slowed down or restless, and suicidal thoughts over the past two weeks. Previous research has established the simple scoring method of a score $\geq 10$ as the best cut-off to detect moderate depression $[27,28]$, hence, individuals scoring 10 or more were considered at high risk of depression. In the case of missing data (only possible on one item as per inclusion criteria), the missing value was imputed with the scale mean (in $1.8 \%$ of respondents) [29].

\subsection{Statistical Analysis}

Analyses were performed in R (v.3.6.1) [30] using the package "survey" (v.3.37) [31], and following the analytic guidelines provided by NHANES [22]. The provided sample weights (combined across the used waves) were applied in all analyses unless otherwise specified.

The two populations (recent and long-term survivors) were compared on basic demographic and health data using chi-square and $t$-tests. The prevalence of depression was estimated for each population overall and as a function of cancer site and years elapsed 
since diagnosis. Confidence intervals at $95 \%$ were calculated using the Korn and Graubard method as implemented in the package "survey".

The prevalence in cancer survivors was then compared to the prevalence found in the matched control populations without cancer history using two approaches: simple conditional logistic regressions for paired case-control data (clogit function in the package "survival" (v. 3.1-8) [32]), which ignores the sampling weights but considers the paired nature of the data, and chi-square tests (svychisq function the package "survey"), which considers the sampling weights but ignores the paired nature of the data. This was done because of the lack of an analytical approach that accommodates unequal sampling weights in matched case-control data.

The relationship between comorbidities and depression (PHQ-9 $\geq 10$ vs. PHQ-9 $<10$ ) was investigated in each population using multiple logistic regression models adjusted for age, sex, race, education, civil status, health insurance status, years since diagnosis, cancer site, and physical functioning limitations. When investigating the relationship in subgroups based on diagnosis, due to the smaller sample sizes, models were adjusted only for the significant predictors in the model of the whole population. The contribution of each specific comorbidity to depression was also investigated using multiple logistic regression controlling for socio-demographic and health-related factors and including each comorbidity as a separate predictor. Analyses were conducted both including and excluding patients with SNM because this cancer is very common, rarely life threatening, and is frequently considered as a different entity.

\section{Results}

Demographic data and comparisons between short and long-term survivors are shown in Table 1. Compared to short-term survivors, long-term survivors were more likely to be female, older, and from an ethnic minority classified as "other". The prevalence of SNM cancer was higher among recent survivors, whereas the prevalence of gynecological cancers was higher among long-term survivors (Table 1). The two groups did not differ on the number of total comorbidities, however, recent survivors reported a significantly larger number of comorbidities diagnosed before the cancer, whereas long-term survivors reported a larger number of comorbidities diagnosed after the cancer.

Table 1. Basic demographic and clinical characteristics of recent and long-term cancer survivors.

\begin{tabular}{|c|c|c|c|c|}
\hline Variable & Category & $\begin{array}{l}\text { Recent Survivors } \\
n=853\end{array}$ & $\begin{array}{l}\text { Long-Term Survivors } \\
\qquad n=1220\end{array}$ & $p$ \\
\hline \multirow{2}{*}{ Sex } & Male & 49.4 & 40.9 & \multirow[t]{2}{*}{0.007} \\
\hline & Female & 50.6 & 59.1 & \\
\hline \multirow{4}{*}{ Age } & $\mathrm{M} \pm \mathrm{SD}$ & $58.6(13.1)$ & $61.2(11.9)$ & \multirow[t]{4}{*}{0.001} \\
\hline & $18-39$ & 10.4 & 6.9 & \\
\hline & $40-59$ & 37.2 & 31.4 & \\
\hline & $60-79$ & 52.4 & 61.7 & \\
\hline \multirow{5}{*}{ Race } & Non-Hispanic White & 85.3 & 83.9 & \multirow[t]{5}{*}{0.006} \\
\hline & Non-Hispanic Black & 6.7 & 5.3 & \\
\hline & Other Hispanic & 2.8 & 2.8 & \\
\hline & Mexican American & 2.7 & 2.9 & \\
\hline & Other & 2.5 & 5.1 & \\
\hline \multirow{5}{*}{ Education } & Less than 9th grade & 2.8 & 3.2 & \multirow[t]{5}{*}{0.707} \\
\hline & 9-11th grade & 7.8 & 6.6 & \\
\hline & High school graduate/GED & 20.8 & 19.5 & \\
\hline & Some college or AA degree & 33.1 & 32.5 & \\
\hline & College graduate or above & 35.5 & 38.2 & \\
\hline
\end{tabular}


Table 1. Cont.

\begin{tabular}{|c|c|c|c|c|}
\hline Variable & Category & $\begin{array}{l}\text { Recent Survivors } \\
n=853\end{array}$ & $\begin{array}{l}\text { Long-Term Survivors } \\
\qquad \mathrm{n}=1220\end{array}$ & $p$ \\
\hline \multirow{4}{*}{ Civil status } & Married or living with partner & 70.1 & 68.2 & 0.052 \\
\hline & Divorced or separated & 14.8 & 17.3 & \\
\hline & Single, never married & 8.2 & 5.2 & \\
\hline & Widowed & 6.9 & 9.3 & \\
\hline \multirow{2}{*}{ Insurance status } & Insured & 95.4 & 92.8 & 0.095 \\
\hline & Uninsured & 4.6 & 7.2 & \\
\hline \multirow{8}{*}{ Cancer site } & Skin non-melanoma & 27.7 & 19.7 & $<0.001$ \\
\hline & Melanoma & 6.8 & 7.7 & \\
\hline & Skin unknown type & 8.6 & 8.5 & \\
\hline & Breast & 13.8 & 15.2 & \\
\hline & Gynecological & 7.9 & 18.6 & \\
\hline & Genitourinary & 13.8 & 12.7 & \\
\hline & Gastrointestinal & 6.2 & 4.4 & \\
\hline & Other & 15.2 & 13.1 & \\
\hline \multirow{8}{*}{ Years since diagnosis } & 1 year & 35.2 & - & - \\
\hline & 2 years & 18.4 & - & \\
\hline & 3 years & 17.1 & - & \\
\hline & 4 years & 14.3 & - & \\
\hline & 5 years & 15.0 & - & \\
\hline & $6-10$ years & - & 40.6 & \\
\hline & $11-20$ years & - & 34.9 & \\
\hline & $20+$ years & - & 24.5 & \\
\hline \multirow{5}{*}{ Comorbidities total } & $\mathrm{M} \pm \mathrm{SD}$ & $2.61(2.06)$ & $2.67(2.01)$ & 0.704 \\
\hline & None & 15.6 & 10.2 & \\
\hline & One & 17.8 & 22.7 & \\
\hline & Two & 19.9 & 20.1 & \\
\hline & Three or more & 46.7 & 47.0 & \\
\hline \multirow{5}{*}{$\begin{array}{l}\text { Comorbidities } \\
\text { pre-diagnosis }\end{array}$} & $\mathrm{M} \pm \mathrm{SD}$ & $2.45(1.83)$ & $1.21(1.32)$ & $<0.001$ \\
\hline & None & 10.1 & 35.8 & \\
\hline & One & 24.5 & 32.6 & \\
\hline & Two & 23.9 & 16.5 & \\
\hline & Three or more & 41.5 & 15.0 & \\
\hline \multirow{4}{*}{$\begin{array}{l}\text { Comorbidities } \\
\text { post-diagnosis }\end{array}$} & $\mathrm{M} \pm \mathrm{SD}$ & $0.55(0.78)$ & $1.84(1.44)$ & $<0.001$ \\
\hline & None & 58.2 & 14.5 & \\
\hline & One & 31.9 & 33.4 & \\
\hline & Two or more & 9.9 & 52.1 & \\
\hline \multirow{3}{*}{$\begin{array}{l}\text { Physical function } \\
\text { limitations }\end{array}$} & No limitations & 64.6 & 62.2 & 0.431 \\
\hline & Limited & 20.1 & 23.2 & \\
\hline & Disabled & 15.3 & 14.6 & \\
\hline \multirow{2}{*}{$\begin{array}{c}\text { Depression (PHQ-9 } \geq \\
10)\end{array}$} & Depressed & 8.4 & 8.8 & 0.754 \\
\hline & Not depressed & 91.6 & 91.2 & \\
\hline
\end{tabular}

Note: Values are percentages for categorical variables and mean and standard deviation, M(SD), for age and number of comorbidities. $p$-values are from chi-square tests comparing recent and long-term survivors for categorical variables and from $t$-tests for age and the number of comorbidities.

\subsection{Recent Survivors}

The prevalence of depression (PHQ-9 $\geq 10$ ) was 10.3\% (95\% CI 7.2-13.5) in the population of recent survivors (excluding SNM, see Table 2). Except for diagnoses of SNM, "other", and "skin unknown type" cancers, the prevalence of depression was consistently higher in recent survivors compared to controls, albeit significantly so only during the first year after diagnosis and for gynecological cancers (Table 2). 


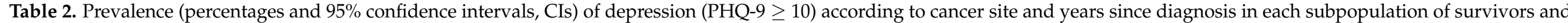
their controls.

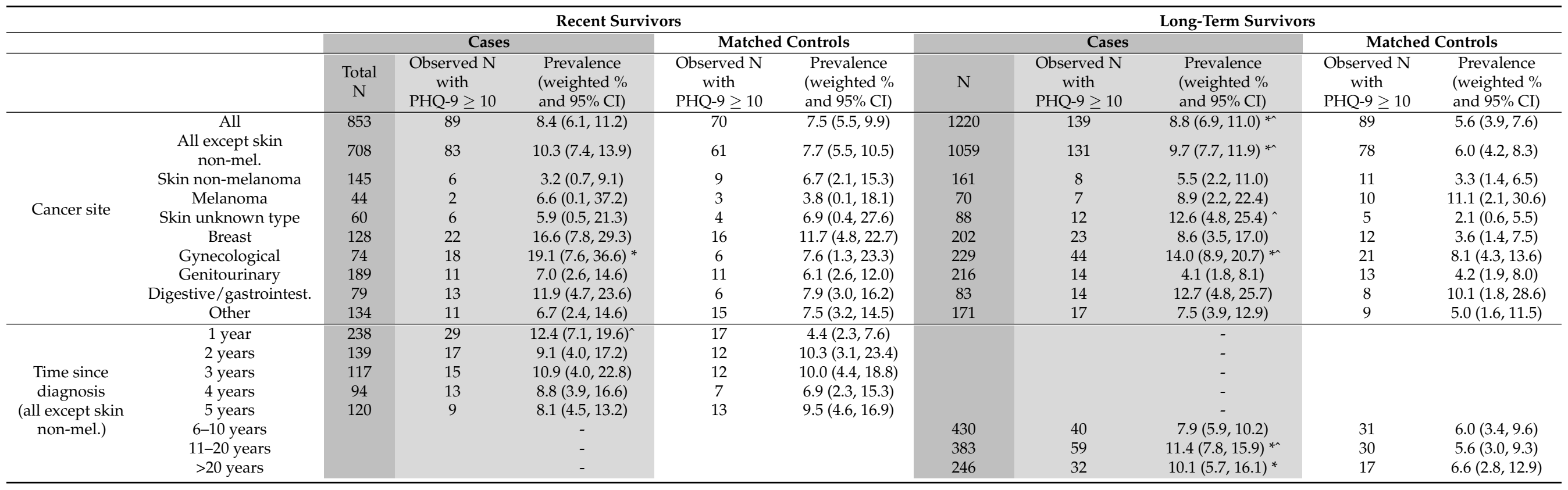

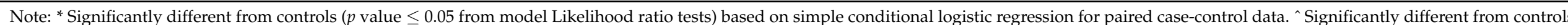

$(p$ value $\leq 0.05)$ based on chi-square test in the "survey" package. Note that observed N/total N does not equal the estimated prevalence, which is derived using the sampling weights. 
The most prevalent comorbidities in this population were obesity, hypertension, arthritis, asthma, diabetes, thyroid problems, and chronic bronchitis (see Table A2 in the Appendix A). The prevalence of depression was higher among survivors who reported more comorbidities: the prevalence among those reporting no comorbidities was $1.9 \%$, compared to $3.3 \%$ among those reporting one, $5.7 \%$ two, and $13.6 \%$ three or more comorbidities.

Total number of comorbidities. In multiple regression controlling for sociodemographic and health-related factors, the total number of comorbidities was significantly related to depression: each additional comorbidity increased the odds of suffering depression according to the PHQ-9 by about 50\% (OR $=1.54,95 \%$ CI 1.29-1.84, see Table 3). Suffering one comorbidity vs. none did not significantly increase the risk of depression, $\mathrm{OR}=2.41,95 \%$ CI $0.54-10.72$, but suffering multimorbidity (two or more comorbidities) did with OR $=8.12,95 \%$ CI 2.23-29.60 in the whole sample and OR $=6.75,95 \%$ CI $1.80-25.25$ excluding survivors of SNM.

Table 3. Effect of comorbidities on depression (PHQ-9 $\geq 10$ ) overall and according to cancer site in recent cancer survivors $(\mathrm{n}=853)$.

\begin{tabular}{|c|c|c|c|}
\hline Table & & $\begin{array}{c}\text { Comorbidities } \\
\text { Total }\end{array}$ & $\begin{array}{l}\text { Comorbidities } \\
\text { Pre-Diagnosis }\end{array}$ \\
\hline & $\mathrm{N}$ & OR $(95 \% \mathrm{CI})$ & OR $(95 \% \mathrm{CI})$ \\
\hline All * & 853 & $1.54(1.29,1.84)$ & $1.51(1.22,1.87)$ \\
\hline All except skin non-melanoma * & 708 & $1.57(1.30,1.89)$ & $1.63(1.30,2.03)$ \\
\hline Skin non-melanoma ${ }^{* *}$ & 145 & $1.52(1.00,2.30)$ & $1.45(1.10,1.91)$ \\
\hline Skin (melanoma and skin unknown type) ** & 104 & $1.39(0.87,2.20)$ & $1.39(0.87,2.21)$ \\
\hline Breast $* *$ & 128 & $2.49(1.63,3.81)$ & $2.32(1.60,3.36)$ \\
\hline Gynecological ** & 74 & $1.53(1.12,2.09)$ & $1.40(0.96,2.05)$ \\
\hline Genitourinary ** & 189 & $1.61(1.20,2.16)$ & $1.77(1.16,2.70)$ \\
\hline Digestive/gastrointestinal ** & 79 & $0.95(0.65,1.39)$ & $1.02(0.63,1.64)$ \\
\hline Skin ** & 104 & $1.39(0.87,2.20)$ & $1.39(0.87,2.21)$ \\
\hline Other $* *$ & 134 & $1.32(0.84,2.06)$ & $1.14(0.78,1.66)$ \\
\hline
\end{tabular}

Note: * From a multiple regression model controlling for age, sex, race, education, civil status, insurance status, years since diagnosis, cancer site, and physical functioning limitations. ${ }^{*}$ From a multiple regression model controlling for age and physical functioning limitations. Melanoma and skin unknown type were combined for this analysis due to their small sample sizes but similarity in depression prevalence.

The relationship between comorbidities and depression was strongest among recent survivors of breast cancer, followed by genitourinary and gynecological cancers.

Besides comorbidities, the other significant predictors of depression were age and physical function limitations. Younger patients were more likely to report depression with OR $=3.74,95 \%$ CI 1.70-8.21 for the 40-59 vs. $60+$ group, and OR $=10.37,95 \% \mathrm{CI}$ 3.17-33.90 for the 20-39 vs. 60+ group. Survivors who were disabled were also more likely to report depression compared to survivors without physical limitations, OR $=3.60,95 \%$ CI 1.41-9.19.

Comorbidities diagnosed before the cancer. The results were similar when only the comorbidities diagnosed before the cancer were considered, both in the total sample and without considering survivors of SNM (Table 3). Suffering one comorbidity vs. none before the cancer was diagnosed did not significantly increase the risk of depression, $\mathrm{OR}=0.57$, 95\% CI 0.15-2.20, but suffering multimorbidity did with OR $=3.48,95 \%$ CI $1.26-9.55$ in the whole sample, and OR $=7.11,95 \%$ CI 1.69-29.97 excluding patients with SNM.

Comorbidities diagnosed after/at the same time as the cancer. The number of comorbidities diagnosed after the cancer was not significantly related to depression, OR $=1.21$, 95\% CI 0.67-1.87.

Effects of specific comorbidities. The specific comorbidities that were most strongly and significantly related to depression were stroke, kidney disease, hypertension, obesity, asthma, and arthritis (Figure 2). 


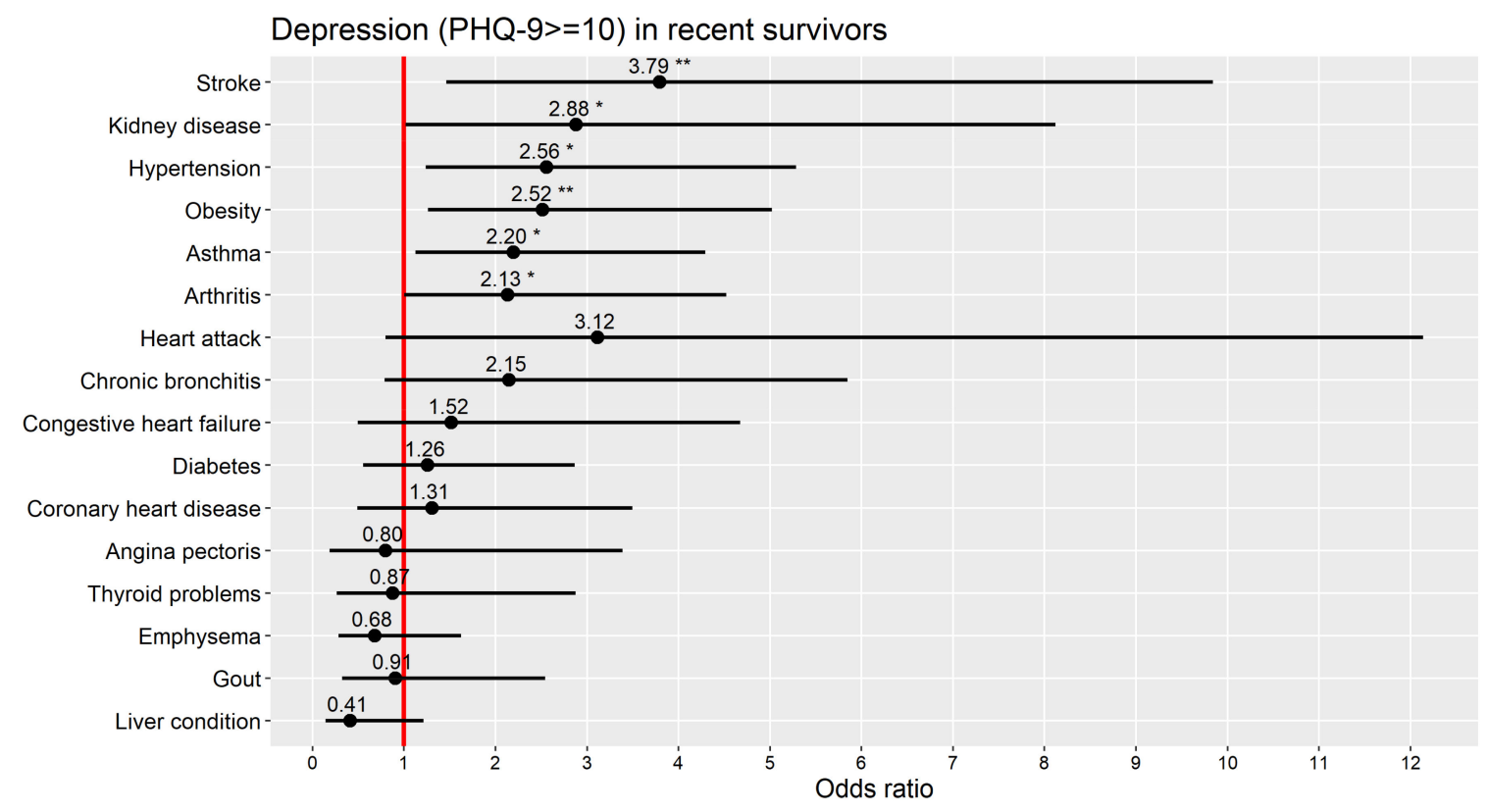

Figure 2. Odds ratios (black dots) and their 95\% confidence intervals (black lines crossing the dots) for individual comorbidities from multiple regression analysis in recent survivors with outcome depression (PHQ-9 $\geq 10$ ) and adjusted for age, sex, race, and years since diagnosis. Red line: $\mathrm{OR}=1$ (no effect). Note: ${ }^{*} p \leq 0.05 .{ }^{* *} p \leq 0.01$. ${ }^{*}$ and ${ }^{* *}$ also denote confidence intervals excluding 1.

\subsection{Long-Term Survivors}

The prevalence of depression (PHQ-9 $\geq 10$ ) was 9.7\% (95\% CI 7.7-11.7) in the population of long-term survivors (excluding SNM, see Table 2). The prevalence of depression was higher in long-term survivors compared to controls, in particular after 10 or more years of survivorship and for survivors of gynecological and skin unknown type cancers (Table 2).

The most prevalent comorbidities in this population were similar to those found in short-term survivors: obesity, arthritis, hypertension, thyroid problems, asthma, diabetes, and chronic bronchitis (see Table A2). The prevalence of depression was higher among longterm survivors who reported more comorbidities: the prevalence among those reporting no comorbidities was 3.0\%, compared to $7.8 \%$ among those reporting one, $8.6 \%$ two, and $10.6 \%$ three or more comorbidities.

However, in multiple regression controlling for sociodemographic and health-related factors, the number of comorbidities was not significantly related to depression, $\mathrm{OR}=1.09$, $95 \%$ CI $0.97-1.23$. This was the case also when only the number of comorbidities diagnosed before or after the cancer was considered, in the total population, and excluding survivors of SNM (all 95\% CIs containing 1).

Instead, the significant predictors of depression in this population were age, education, and physical function limitations. Younger patients were more likely to report depression with $\mathrm{OR}=3.92,95 \%$ CI $2.05-7.49$ for the $40-59$ vs. $60+$ group, and OR $=11.07,95 \% \mathrm{CI}$ 3.73-32.84 for the 20-39 vs. 60+ group. Compared to those who were college graduates or above, survivors who had finished high school or less were more likely to report depression, $\mathrm{OR}=3.40,95 \% \mathrm{CI} 1.64-7.03$. Survivors who were disabled were also more likely to report depression compared to survivors without physical limitations, $\mathrm{OR}=5.57$, 95\% CI 3.03-10.22.

\section{Discussion}

Comorbidities were strongly related to depression as measured by the PHQ-9 questionnaire in recent but not in long-term survivors. This was the case both when considering the 
total number of comorbidities present at the time of the survey and only the comorbidities diagnosed before the cancer. In particular, recent survivors who suffered multimorbidity (two or more physical conditions) before their cancer was diagnosed had 3 to 4 times the odds of reporting significant depressive symptoms up to 5 years after the cancer diagnosis.

This suggests that the number of comorbidities present at the time of diagnosis could be a very important predictor of depression risk up to five years after cancer diagnosis, independent of many demographics and health-related factors such as sex, age, race, or physical functioning limitations. This possibility should be explored in prospective studies and based on confirmed depression diagnoses, and if the current findings are confirmed, the presence of additional comorbidities, in particular multimorbidity, could be used to target prevention efforts or streamline screening for depression during treatment and follow up. Information about comorbidities is usually readily available in medical records and always should be considered during cancer treatment, so no changes would be required to the screening instruments already in use. The prevention and early detection of depression in the cancer setting is of highest importance because patients who develop depression after their cancer diagnosis have shorter survival [33].

Comorbidities were significantly related to depression in SNM, breast, gynecological, and genitourinary cancer survivors. The relationship was strongest in breast cancer survivors, such that each additional comorbidity more than doubled the odds of reporting significant depressive symptoms. These results support the findings of a systematic review which identified comorbidity as a significant factor for distress in breast cancer survivors [34]. In contrast, no relationship was found for survivors of digestive/gastrointestinal cancers, melanoma, skin unknown type cancers, and other cancers.

The comorbidities with the strongest independent effects on depression risk in recent survivors were stroke, kidney disease, hypertension, obesity, asthma, and arthritis, all of which have been previously linked to depression [35-39]. Having in mind that depression risk in this study was driven by multimorbidity, the different comorbidities may interact in important ways. For instance, the clustering of obesity, hypertension, and diabetes into the metabolic syndrome has been associated with depression [37]. Future studies should explore the most detrimental combinations of diseases when it comes to mental health outcomes in cancer survivors.

There are multiple biological, physical, social, and psychological mechanisms through which physical comorbidities could increase the risk of developing depression after a cancer diagnosis (see Figure 3). The comorbidities with the strongest independent effects on depression risk in the current study (Figure 2) included multiple conditions associated with chronic inflammation, suggesting it could be one of the principal mechanisms. A chronic state of inflammation has been implicated in the pathogenesis of depression [40-42], multiple types of cancer including breast, colorectal, lung, ovarian, and prostate cancer [43], and the chronic conditions that most frequently co-exist in cancer patients (i.e., cardiovascular conditions, obesity, metabolic, and autoimmune disorders) [44-46].

Another related biological mechanism is increased allostatic load: the cumulative biological burden on the body's systems due to repeated adaptation to stressors over time, reflected in cardiovascular, metabolic, and immunological system parameters $[47,48]$. Finally, some medications for cancer are known to increase depression risk $[6,40]$ and the medications used to treat the co-existing conditions could interact in unknown ways to increase this risk. 


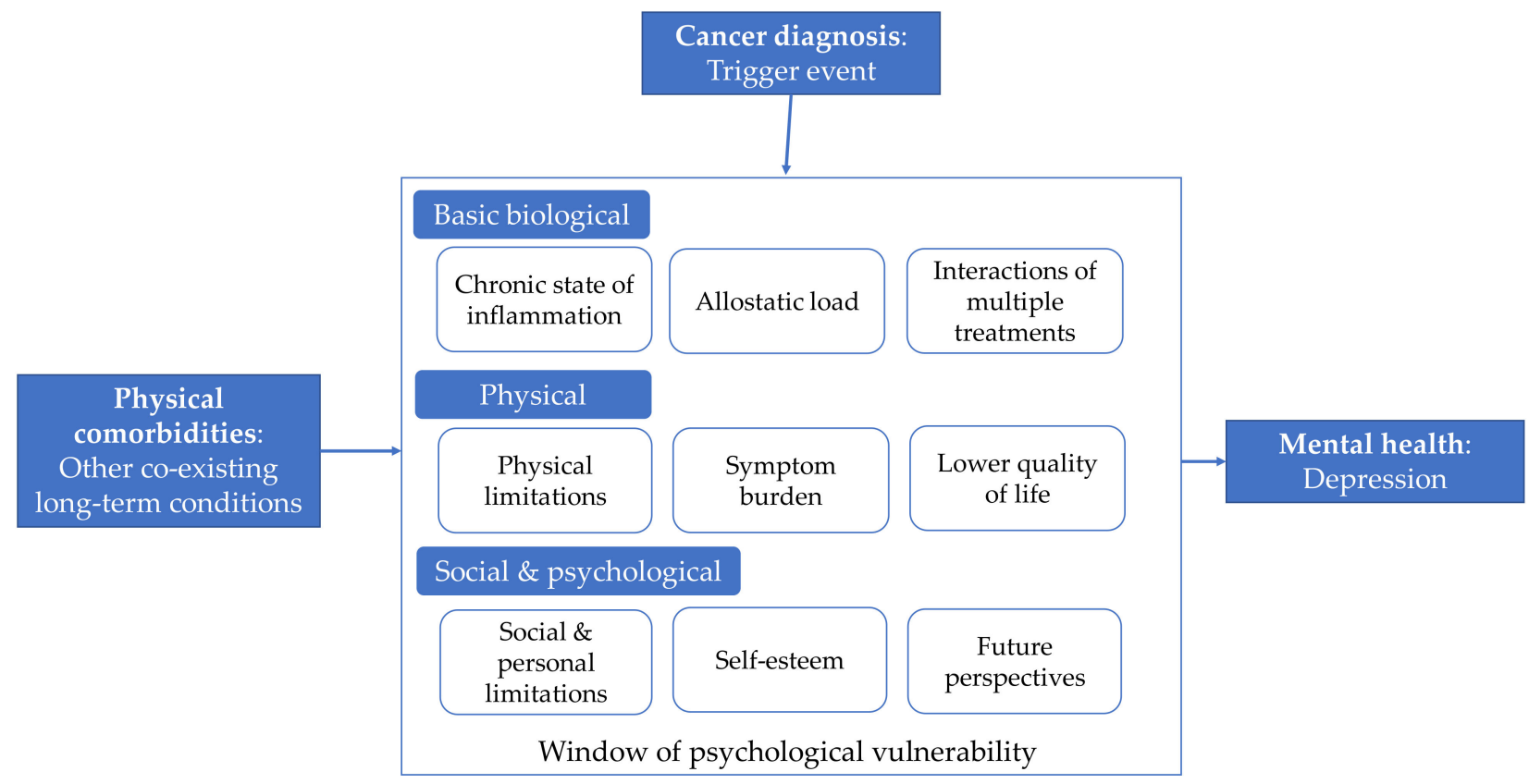

Figure 3. Theoretical model of potential mechanisms through which physical comorbidities could increase the risk of mental health problems such as depression following a cancer diagnosis.

Physical mechanisms include more physical limitations, higher symptom burden, and lower quality of life among patients with more comorbidities [49,50]. In the current study, the relationship between comorbidities was significant even when controlling for physical function limitations, which is one potential mechanism through which comorbidities could influence mental health. In other words, knowing the patient's physical limitations status (i.e., whether they are disabled to a certain extent) would be useful but not optimal to predict depression risk and it would be worth exploring the other potential mechanisms.

Finally, social and psychological mechanisms include the experience of different social and personal limitations due to multi-morbidity [40], lower self-esteem resulting from disease labeling or inability to fulfil social or family functions [40,51,52], or lower hopes for the future due to worse cancer prognosis [14]. In summary, the usually readily available and simple information about the number of comorbidities could capture and summarize the multidimensional underlying biological, social, and psychological risk.

Comorbidity was not significantly related to depression in long-term survivors, even when physical functioning - a potential underlying mechanism - was not included in the model. This suggests that information about comorbidity may be of little utility for screening of long-term survivors, at least those without second cancers and who are well enough to participate in an extensive survey. It appears that comorbidity may have an effect on mental health only during the "window of psychological vulnerability" produced after the cancer diagnosis when the physical, psychological, and social impact of the cancer diagnosis and treatment is highest.

The mental health of cancer survivors during long-term survivorship is much less researched compared to the first few years after diagnosis [9]. On one hand, research shows that once beyond the symbolic 5-year mark, when most cancer follow-up schedules are discontinued, individuals begin to identify as "survivors" or "ex-patients" as opposed to "patients" or "victims" [52]. This transformation has been related to the disappearance of symptoms and disability and the reception of assuring test results after treatment success [52]. Perhaps this change in disease-related identify and the associated increase in well-being could buffer the negative effect of comorbidities in long-term survivors. On the other hand, cancer patients who suffer multimorbidity [14] and depression [33] after their cancer diagnosis have higher mortality rates. Thus, individuals who are psychologically 
the most vulnerable to the clustering of different comorbidities may be less likely to make it into long-term survivorship.

Contrary to the results of a recent review [9], we found that the prevalence of depression was higher in long-term survivors compared to controls matched on several demographic characteristics. Interestingly, this was the case for survivors beyond 10 years from diagnosis, a period that is much less frequently researched. Cancer patients can suffer diverse physical and psychological sequelae and symptoms for longer than 10 years after treatment [53]. This could contribute to the higher rates of depression found in this population, which was nevertheless not related to the presence of comorbidities.

Depression was also significantly more prevalent among survivors of gynecological cancers regardless of the time elapsed after diagnosis. Gynecological cancer survivors were the youngest in the current study (mean age of 47 and 55 in short and long-term survivors, respectively). Survivors of gynecological cancers experience diverse persistent sequelae such as sexual problems, premature menopause, pain, and fatigue, which can have implications for quality and life and ultimately mental health [54].

Limitations of this study include the use of a self-report instrument instead of full clinical interview as a measure of depression. No information was available regarding the stage of disease at the time of diagnosis, or the treatments received, and individuals 80 years old or older had to be excluded. We did not control for lifestyle factors such as alcohol use, nutrition, exercise, or sleep that could also influence depression risk [55].

There was only a small number of survivors with certain cancer diagnoses which prevented us from investigating the role of comorbidities in patients diagnosed with these tumors (e.g., head and neck, pancreatic, lung). Some of these cancers have very low survival rates and hence the prevalence of survivors in the population would be also low, especially in the long-term group. In addition, whereas the total sample size of survivors was relatively large, subgroup analyses of the different types of cancer were based on a much smaller number of respondents (between 74 and 145). Hence, a small or medium effect of comorbidities on depressive symptoms may exist also in the subgroups where it was not significant; however, most subgroup analyses conducted were only powered to detect large effect sizes (see Sensitivity analyses on OSF: https://osf.io/uqcy4/, doi 10.17605/OSF.IO/UQCY4, accessed on 5 July 2021).

The assessment of comorbidities and the cancer diagnosis could be affected by recall bias. Previous studies based on NHANES and other cohorts examined the validity of self-reported diagnoses of diverse chronic conditions against medical records or cancer registry data [56,57]. These studies indicate that accuracy, although generally acceptable, varies strongly by condition. In the NHANES waves used in the current study, to assess when each condition was diagnosed, respondents had to indicate how old they were when it was first diagnosed. We believe that this general question, together with the fact that a cancer diagnosis is usually a very impactful and thus memorable event, provides an effective benchmarking technique to determine which comorbidities were present before and which after the cancer diagnosis. However, the validity of this self-reported method should be examined empirically in future studies and ideally multiple sources should be used to achieve the highest possible accuracy $[56,57]$.

Cancer patients with previous history of a psychiatric disorder, current depression, or a substance use disorder are considered at higher risk for psychological distress following a cancer diagnosis [20]. However, no information regarding previous history of the psychiatric conditions of psychological distress was available. In future studies, it would be important to address the joint effects of physical and psychiatric comorbidities on depression risk, as these could interact in important ways. Finally, there could be further physical comorbidities that contribute to depression but were not assessed in the survey.

\section{Conclusions}

In conclusion, multimorbidity before and after the cancer diagnosis was significantly related to depression only in recent cancer survivors (up to 5 years after diagnosis). The 
relationship was strongest for breast cancer followed by genitourinary, and gynecological cancer survivors. Future research should explore the utility of information about comorbidities in the triage of screening and full clinical evaluation for depression in cancer survivors.

Author Contributions: Conceptualization, D.P., A.C., M.-J.S. methodology, D.P., A.C., M.R.-B.; investigation: D.P., A.C., M.R.-B., D.R.-S., E.B.-L., R.G.-R., J.-J.J.-M., M.-J.S.; software, D.P., D.R.-S.; validation, D.P., D.R.-S.; formal analysis, D.P., D.R.-S., M.R.-B.; data curation, D.R.-S.; writingoriginal draft preparation, D.P.; Writing-Review and Editing, A.C., M.R.-B., D.R.-S., E.B.-L., R.G.-R., J.-J.J-M., M.-J.S.; visualization, D.P., D.R.-S.; supervision, M.-J.S.; funding acquisition, D.P., M.-J.S. All authors have read and agreed to the published version of the manuscript.

Funding: Dafina Petrova is supported by a Sara Borrell fellowship from the Health Institute Carlos III (Expde: CD19/00203).

Institutional Review Board Statement: The NHANES survey was approved by the National Center for Health Statistics Institutional Review Board. The study reported in this manuscript was exempt from ethical committee approval because it was based on publicly available data.

Informed Consent Statement: Informed consent was obtained from all participants before participating in the NHANES survey.

Data Availability Statement: The data used for this research are publicly available on the NHANES website: https:/ /www.cdc.gov/nchs/nhanes/index.htm, accessed on 5 July 2021. The dataset and analysis for this specific study are available on the Open Science Framework (OSF): doi:10.17605/OSF.IO/UQCY4, https:/ / osf.io/uqcy4/, accessed on 5 July 2021.

Conflicts of Interest: The authors declare no conflict of interest.

\section{Appendix A}

Table A1. Grouping of different cancer types according to body location/system and number of respondents reporting each cancer type among recent and long-term survivors.

\begin{tabular}{|c|c|c|c|c|}
\hline NHANES Code & Cancer & $\begin{array}{l}\text { N Recent } \\
\text { Survivors }\end{array}$ & $\begin{array}{l}\text { N Long-Term } \\
\text { Survivors }\end{array}$ & $\begin{array}{l}\text { Group According to } \\
\text { Body Location/System }\end{array}$ \\
\hline 10 & Bladder & 18 & 17 & Genitorunary \\
\hline 11 & Blood & 1 & 1 & Other \\
\hline 12 & Bone & 4 & 2 & Other \\
\hline 13 & Brain & 3 & 7 & Other \\
\hline 14 & Breast & 128 & 202 & Breast \\
\hline 15 & Cervix (cervical) & 32 & 124 & Gynecological \\
\hline 16 & Colon & 52 & 59 & Digestive/gastrointestinal \\
\hline 17 & Esophagus (esophageal) & 5 & 6 & Digestive/gastrointestinal \\
\hline 18 & Gallbladder & 0 & 1 & Digestive/gastrointestinal \\
\hline 19 & Kidney & 15 & 22 & Genitorunary \\
\hline 20 & Larynx/windpipe & 2 & 5 & Other \\
\hline 21 & Leukemia & 8 & 9 & Other \\
\hline 22 & Liver & 6 & 2 & Digestive/gastrointestinal \\
\hline 23 & Lung & 31 & 12 & Other \\
\hline 24 & Lymphoma/Hodgkin's disease & 24 & 28 & Other \\
\hline 25 & Melanoma & 44 & 70 & Melanoma \\
\hline
\end{tabular}


Table A1. Cont.

\begin{tabular}{|c|c|c|c|c|}
\hline NHANES Code & Cancer & $\begin{array}{l}\text { N Recent } \\
\text { Survivors }\end{array}$ & $\begin{array}{l}\text { N Long-Term } \\
\text { Survivors }\end{array}$ & $\begin{array}{l}\text { Group According to } \\
\text { Body Location/System }\end{array}$ \\
\hline 26 & Mouth/tongue/lip & 3 & 9 & Other \\
\hline 27 & Nervous system & 0 & 1 & Other \\
\hline 28 & Ovary (ovarian) & 14 & 37 & Gynecological \\
\hline 29 & Pancreas (pancreatic) & 6 & 2 & Digestive/gastrointestinal \\
\hline 30 & Prostate & 154 & 165 & Genitorunary \\
\hline 31 & Rectum (rectal) & 3 & 5 & Digestive/gastrointestinal \\
\hline 32 & Skin non-melanoma & 145 & 161 & Skin non-melanoma \\
\hline 33 & Skin (don't know what kind) & 60 & 88 & Skin unknown kind \\
\hline 34 & Soft tissue (muscle or fat) & 0 & 3 & Other \\
\hline 35 & Stomach & 7 & 8 & Digestive/gastrointestinal \\
\hline 36 & Testis (testicular) & 2 & 12 & Genitorunary \\
\hline 37 & Thyroid & 17 & 34 & Other \\
\hline 38 & Uterus (uterine) & 28 & 68 & Gynecological \\
\hline 39 & Other & 41 & 60 & Other \\
\hline
\end{tabular}

Table A2. Prevalence of different comorbidities in recent and long-term cancer survivors.

\begin{tabular}{|c|c|c|}
\hline & $\begin{array}{l}\text { Recent Survivors } \\
\mathrm{n}=853\end{array}$ & $\begin{array}{l}\text { Long-Term Survivors } \\
\mathrm{n}=1220\end{array}$ \\
\hline & Percentage $(95 \% \mathrm{CI})$ & Percentage $(95 \% \mathrm{CI})$ \\
\hline Obesity $\left(\mathrm{BMI} \geq 30 \mathrm{~kg} / \mathrm{m}^{2}\right) *$ & $51.9(46.8,57.1)$ & $53.1(49.7,56.5)$ \\
\hline Hypertension & $51.2(46.4,56.0)$ & $48.5(44.5,52.4)$ \\
\hline Arthritis & $43.7(38.8,48.4)$ & $50.6(46.7,54.4)$ \\
\hline Asthma & $17.9(14.1,21.8)$ & $17.4(14.4,20.4)$ \\
\hline Diabetes & $17.8(14.3,21.2)$ & $15.4(12.7,18.1)$ \\
\hline Thyroid problems & $15.3(12.4,18.3)$ & $19.9(16.7,23.1)$ \\
\hline Chronic bronchitis & $10.6(8.1,13.1)$ & $10.7(7.9,13.4)$ \\
\hline Gout & $8.3(5.7,10.9)$ & $8.3(6.4,10.3)$ \\
\hline Coronary heart disease & $6.6(4.6,8.7)$ & $6.2(4.2,8.2)$ \\
\hline Myocardial infarction & $6.2(4.1,8.3)$ & $5.9(4.1,7.8)$ \\
\hline Weak or failing kidneys & $6.1(3.8,8.3)$ & $5.6(3.9,7.1)$ \\
\hline Congestive heart failure & $5.6(3.8,7.5)$ & $4.1(2.8,5.4)$ \\
\hline Emphysema & $5.6(3.7,7.5)$ & $5.3(3.2,7.3)$ \\
\hline Liver condition & $5.6(3.6,7.4)$ & $5.6(4.0,7.1)$ \\
\hline Stroke & $5.1(3.2,7.2)$ & $5.2(3.7,6.7)$ \\
\hline Angina pectoris & $3.3(1.6,5.0)$ & $4.8(2.7,6.8)$ \\
\hline
\end{tabular}

* Calculated based on the highest ever reported weight and current height.

\section{References}

1. Caruso, R.; Breitbart, W. Mental health care in oncology. Contemporary perspective on the psychosocial burden of cancer and evidence-based interventions. Epidemiol. Psychiatr. Sci. 2020, 29, e86. [CrossRef] [PubMed]

2. Nakash, O.; Shemesh, A.; Nagar, M.; Levav, I. Cancer and common mental disorders in the community: Results of the Israel-World Mental Health Survey. Eur. J. Psychiatry 2012, 26, 174-184. [CrossRef] 
3. Ng, H.S.; Roder, D.; Koczwara, B.; Vitry, A. Comorbidity, physical and mental health among cancer patients and survivors: An Australian population-based study. Asia Pac. J. Clin. Oncol. 2018, 14, e181-e192. [CrossRef] [PubMed]

4. Petrova, D.; Redondo-Sánchez, D.; Rodríguez-Barranco, M.; Ruiz, A.R.; Catena, A.; Garcia-Retamero, R.; Sánchez, M. Physical comorbidities as a marker for high risk of psychological distress in cancer patients. Psychooncology 2021. [CrossRef]

5. Mitchell, A.J.; Chan, M.; Bhatti, H.; Halton, M.; Grassi, L.; Johansen, C.; Meader, N. Prevalence of depression, anxiety, and adjustment disorder in oncological, haematological, and palliative-care settings: A meta-analysis of 94 interview-based studies. Lancet Oncol. 2011, 12, 160-174. [CrossRef]

6. Caruso, R.; Nanni, M.G.; Riba, M.; Sabato, S.; Mitchell, A.J.; Croce, E.; Grassi, L. Depressive spectrum disorders in cancer: Prevalence, risk factors and screening for depression: A critical review. Acta Oncol. 2017, 56, 146-155. [CrossRef] [PubMed]

7. Linden, W.; Vodermaier, A.; MacKenzie, R.; Greig, D. Anxiety and depression after cancer diagnosis: Prevalence rates by cancer type, gender, and age. J. Affect. Disord. 2012, 141, 343-351. [CrossRef]

8. Mitchell, A.J.; Ferguson, D.W.; Gill, J.; Paul, J.; Symonds, P. Depression and anxiety in long-term cancer survivors compared with spouses and healthy controls: A systematic review and meta-analysis. Lancet Oncol. 2013, 14, 721-732. [CrossRef]

9. Brandenbarg, D.; Maass, S.W.; Geerse, O.P.; Stegmann, M.E.; Handberg, C.; Schroevers, M.J.; Duijts, S.F. A systematic review on the prevalence of symptoms of depression, anxiety and distress in long-term cancer survivors: Implications for primary care. Eur. J. Cancer Care 2019, 28, e13086. [CrossRef]

10. Krebber AM, H.; Buffart, L.M.; Kleijn, G.; Riepma, I.C.; De Bree, R.; Leemans, C.R.; Verdonck-de Leeuw, I.M. Prevalence of depression in cancer patients: A meta-analysis of diagnostic interviews and self-report instruments. Psycho Oncol. 2014, 23, 121-130. [CrossRef]

11. Nezu, A.M.; Nezu, C.M.; Greenberg, L.M.; Salber, K.E. 19 Cancer and Depression. In The Oxford Handbook of Depression and Comorbidity; Oxford University Press: New York, NY, USA, 2014; p. 302.

12. AIHW (Australian Institute of Health and Welfare). Comorbidity of Mental Disorders and Physical Conditions 2007; AIHW: Canberra, Australia, 2017.

13. Sarfati, D.; Koczwara, B.; Jackson, C. The impact of comorbidity on cancer and its treatment. CA Cancer J. Clin. 2016, 66, 337-350. [CrossRef]

14. Sogaard, M.; Thomsen, R.; Bossen, K.S.; Sørensen, H.H.T.; Nørgaard, M. The impact of comorbidity on cancer survival: A review. Clin. Epidemiol. 2013, 5 (Suppl. 1), 3-29. [CrossRef]

15. Luque-Fernandez, M.A.; Redondo-Sanchez, D.; Lee, S.F.; Rodríguez-Barranco, M.; Carmona-García, M.C.; Marcos-Gragera, R.; Sánchez, M.-J. Multimorbidity by patient and tumor factors and time-to-surgery among colorectal cancer patients in Spain: A population-based study. Clin. Epidemiol. 2020, 12, 31-40. [CrossRef]

16. Luque-Fernandez, M.A.; Goncalves, K.; Salamanca-Fernández, E.; Redondo-Sanchez, D.; Lee, S.F.; Rodríguez-Barranco, M.; Carmona-García, M.C.; Marcos-Gragera, R.; Sánchez, M.-J. Multimorbidity and short-term overall mortality among colorectal cancer patients in Spain: A population-based cohort study. Eur. J. Cancer 2020, 129, 4-14. [CrossRef] [PubMed]

17. Pilling, S.; Anderson, I.; Goldberg, D.; Meader, N.; Taylor, C. Depression in adults, including those with a chronic physical health problem: summary of NICE guidance. BMJ 2009, 339, b4108. [CrossRef] [PubMed]

18. Mausbach, B.T.; Irwin, S.A. Depression and healthcare service utilization in patients with cancer. Psychooncology 2017, 26, 1133-1139. [CrossRef] [PubMed]

19. Donovan, K.A.; Grassi, L.; Deshields, T.L.; Corbett, C.; Riba, M.B. Advancing the science of distress screening and management in cancer care. Epidemiol. Psychiatr. Sci. 2020, 29, e85. [CrossRef] [PubMed]

20. Riba, M.B.; Donovan, K.A.; Andersen, B.; Braun, I.; Breitbart, W.S.; Brewer, B.W.; Buchmann, L.O.; Clark, M.M.; Collins, M.; Corbett, C.; et al. Distress management, version 3.2019, NCCN clinical practice guidelines in oncology. J. Natl. Compr. Cancer Netw. 2019, 17, 1229-1249. [CrossRef]

21. Götz, A.; Kröner, A.; Jenewein, J.; Spirig, R. Evaluation of the adherence of distress screening with the distress thermometer in cancer patients 4 years after implementation. Support. Care Cancer 2018, 27, 2799-2807. [CrossRef] [PubMed]

22. Centers for Disease Control and Prevention (CDC); National Center for Health Statistics (NCHS). National Health and Nutrition Examination Survey Data. Hyattsville, MD: U.S. Department of Health and Human Services, Centers for Disease Control and Prevention. 2007-2018. Available online: https://www.cdc.gov/nchs/nhanes/index.htm (accessed on 5 July 2021).

23. Steeves, J.A.; Shiroma, E.J.; Conger, S.A.; Van Domelen, D.; Harris, T.B. Physical activity patterns and multimorbidity burden of older adults with different levels of functional status: NHANES 2003-2006. Disabil. Health J. 2019, 12, 495-502. [CrossRef] [PubMed]

24. National cancer Institute (NCI). Cancers by Body Location/System. 2021. Available online: https://www.cancer.gov/types/bybody-location (accessed on 5 July 2021).

25. Kroenke, K.; Spitzer, R.L.; Williams, J.B. The PHQ-9: Validity of a brief depression severity measure. J. Gen. Intern. Med. 2001, 16, 606-613. [CrossRef]

26. Hinz, A.; Mehnert, A.; Kocalevent, R.-D.; Brähler, E.; Forkmann, T.; Singer, S.; Schulte, T. Assessment of depression severity with the PHQ-9 in cancer patients and in the general population. BMC Psychiatry 2016, 16, 1-8. [CrossRef] [PubMed]

27. Moriarty, A.S.; Gilbody, S.; McMillan, D.; Manea, L. Screening and case finding for major depressive disorder using the Patient Health Questionnaire (PHQ-9): A meta-analysis. Gen. Hosp. Psychiatry 2015, 37, 567-576. [CrossRef] [PubMed] 
28. Manea, L.; Gilbody, S.; McMillan, D. A diagnostic meta-analysis of the Patient Health Questionnaire-9 (PHQ-9) algorithm scoring method as a screen for depression. Gen. Hosp. Psychiatry 2015, 37, 67-75. [CrossRef] [PubMed]

29. Kroenke, K.; Spitzer, R.L.; Williams, J.B.; Löwe, B. The patient health questionnaire somatic, anxiety, and depressive symptom scales: A systematic review. Gen. Hosp. Psychiatry 2010, 32, 345-359. [CrossRef] [PubMed]

30. R Core Team. R: A Language and Environment for Statistical Computing. R Foundation for Statistical Computing, Vienna, Austria. 2021. Available online: https:/ / www.R-project.org/ (accessed on 5 July 2021).

31. Lumley, T. Package 'Survey'. Available online: http:/ / cran.r2020 (accessed on 5 July 2021).

32. Therneau, T.M.; Lumley, T. Package 'Survival'. CRAN 2014, 2, 3.

33. Pinquart, M.; Duberstein, P.R. Depression and cancer mortality: A meta-analysis. Psychol. Med. 2010, 40, 1797-1810. [CrossRef]

34. Syrowatka, A.; Motulsky, A.; Kurteva, S.; Hanley, J.A.; Dixon, W.G.; Meguerditchian, A.N.; Tamblyn, R. Predictors of distress in female breast cancer survivors: A systematic review. Breast Cancer Res. Treat. 2017, 165, 229-245. [CrossRef]

35. Robinson, R.G.; Jorge, R.E. Post-stroke depression: A review. Am. J. Psychiatry 2016, 173, 221-231. [CrossRef]

36. Bautovich, A.; Katz, I.; Smith, M.; Loo, C.; Harvey, S. Depression and chronic kidney disease: A review for clinicians. Aust. N. Z. J. Psychiatry 2014, 48, 530-541. [CrossRef]

37. Pan, A.; Keum, N.; Okereke, O.I.; Sun, Q.; Kivimaki, M.; Rubin, R.R.; Hu, F.B. Bidirectional association between depression and metabolic syndrome: A systematic review and meta-analysis of epidemiological studies. Diabetes Care 2012, 35, 1171-1180. [CrossRef]

38. Opolski, M.; Wilson, I. Asthma and depression: A pragmatic review of the literature and recommendations for future research. Clin. Pract. Epidemiol. Ment. Health 2005, 1, 18. [CrossRef]

39. Matcham, F.; Rayner, L.; Steer, S.; Hotopf, M. The prevalence of depression in rheumatoid arthritis: A systematic review and meta-analysis. Rheumatology 2013, 52, 2136-2148. [CrossRef]

40. Smith, H.R. Depression in cancer patients: Pathogenesis, implications and treatment. Oncol. Lett. 2015, 9, 1509-1514. [CrossRef]

41. Goldsmith, D.R.; Rapaport, M.H.; Miller, B.J. A meta-analysis of blood cytokine network alterations in psychiatric patients: Comparisons between schizophrenia, bipolar disorder and depression. Mol. Psychiatry 2016, 21, 1696-1709. [CrossRef]

42. Osimo, E.F.; Baxter, L.J.; Lewis, G.; Jones, P.B.; Khandaker, G.M. Prevalence of low-grade inflammation in depression: A systematic review and meta-analysis of CRP levels. Psychol. Med. 2019, 49, 1958-1970. [CrossRef]

43. Michels, N.; van Aart, C.; Morisse, J.; Mullee, A.; Huybrechts, I. Chronic inflammation towards cancer incidence: A systematic review and meta-analysis of epidemiological studies. Crit. Rev. Oncol. 2021, 157, 103177. [CrossRef] [PubMed]

44. Prasad, S.; Sung, B.; Aggarwal, B.B. Age-associated chronic diseases require age-old medicine: Role of chronic inflammation. Prev. Med. 2012, 54, S29-S37. [CrossRef] [PubMed]

45. EEdwards, B.K.; Ms, A.N.; Mariotto, A.B.; Simard, E.P.; Boscoe, F.P.; Henley, S.J.; Jemal, A.; Cho, H.; Anderson, R.N.; Kohler, B.A.; et al. Annual Report to the Nation on the status of cancer, 1975-2010, featuring prevalence of comorbidity and impact on survival among persons with lung, colorectal, breast, or prostate cancer. Cancer 2014, 120, 1290-1314. [CrossRef] [PubMed]

46. Furman, D.; Campisi, J.; Verdin, E.; Carrera-Bastos, P.; Targ, S.; Franceschi, C.; Ferrucci, L.; Gilroy, D.W.; Fasano, A.; Miller, G.W.; et al. Chronic inflammation in the etiology of disease across the life span. Nat. Med. 2019, 25, 1822-1832. [CrossRef] [PubMed]

47. Mathew, A.; Doorenbos, A.Z.; Li, H.; Jang, M.K.; Park, C.G.; Bronas, U.G. Allostatic Load in Cancer: A Systematic Review and Mini Meta-Analysis. Biol. Res. Nurs. 2021, 23, 341-361. [CrossRef]

48. McEwen, B.S. Allostasis and allostatic load: Implications for neuropsychopharmacology. Neuropsychopharmacology 2000, 22, 108-124. [CrossRef]

49. Mao, J.J.; Armstrong, K.; Bowman, M.; Xie, S.X.; Kadakia, R.; Farrar, J.T. Symptom burden among cancer survivors: Impact of age and comorbidity. J. Am. Board Fam. Med. 2007, 20, 434-443. [CrossRef] [PubMed]

50. Smith, A.W.; Reeve, B.B.; Bellizzi, K.M.; Harlan, L.C.; Klabunde, C.N.; Amsellem, M.; Bierman, A.S.; Hays, R.D. Cancer, comorbidities, and health-related quality of life of older adults. Health Care Financ. Rev. 2008, 29, 41-56. [PubMed]

51. Sowislo, J.F.; Orth, U. Does low self-esteem predict depression and anxiety? A meta-analysis of longitudinal studies. Psychol. Bull. 2013, 139, 213-240. [CrossRef]

52. Deimling, G.T.; Bowman, K.F.; Wagner, L.J. Cancer survivorship and identity among long-term survivors. Cancer Investig. 2007, 25, 758-765. [CrossRef]

53. Harrington, C.B.; Hansen, J.A.; Moskowitz, M.; Todd, B.L.; Feuerstein, M. It's not over when it's over: Long-term symptoms in cancer survivors-a systematic review. Int. J. Psychiatry Med. 2010, 40, 163-181. [CrossRef]

54. Gonçalves, V. Long-term quality of life in gynecological cancer survivors. Curr. Opin. Obstet. Gynecol. 2010, 22, 30-35. [CrossRef]

55. Lopresti, A.L.; Hood, S.D.; Drummond, P.D. A review of lifestyle factors that contribute to important pathways associated with major depression: Diet, sleep and exercise. J. Affect. Disord. 2013, 148, 12-27. [CrossRef]

56. Bergmann, M.M.; Calle, E.E.; Mervis, C.A.; Miracle-McMahill, H.L.; Thun, M.J.; Health, C.W. Validity of self-reported cancers in a propsective cohort study in comparison with data from state cancer registries. Am. J. Epidemiol. 1998, 147, 556-562. [CrossRef]

57. Bergmann, M.M.; Byers, T.; Freedman, D.S.; Mokdad, A. Validity of self-reported diagnoses leading to hospitalization: A comparison of self-reports with hospital records in a prospective study of American adults. Am. J. Epidemiol. 1998, 147, 969-977. [CrossRef] [PubMed] 